\title{
Queixa escolar e atendimento psicológico na rede de saúde: contribuições para debate
}

\author{
Gercimeire Ramos Moreira \\ Universidade Federal de Mato Grosso - Cuiabá - MT - Brasil \\ Jane Teresinha Domingues Cotrin \\ Universidade Federal de Mato Grosso - Cuiabá - MT - Brasil
}

\begin{abstract}
Resumo
Este artigo objetiva propor reflexões sobre o atendimento à queixa escolar, especificamente a dificuldade na aprendizagem, feito por psicólogos que atuam na rede de Atenção Secundária à Saúde do município de Cuiabá, estado de Mato Grosso. O estudo está fundamentado na perspectiva crítica em Psicologia e foi realizado a partir de uma pesquisa qualitativa em que buscamos identificar o significado que os profissionais atribuem à queixa escolar, as abordagens teóricas em que se fundamentam e os instrumentos e metodologias utilizados na prática. Os resultados corroboram pesquisas já realizadas em que as queixas escolares constituem uma das maiores demandas recebidas nas unidades de Saúde sendo compreendidas como um fenômeno decorrente de problemas da criança, dos pais e de técnicas de ensino inadequadas. Os resultados também apontam para uma incompatibilidade entre a proposta de atendimento da rede de Atenção Secundária à Saúde e o atendimento à demanda escolar.
\end{abstract}

Palavras-chave: Psicologia escolar; dificuldades escolares; atuação do psicólogo.

\section{School problems and psychological care in the health network: contribution to debate}

\begin{abstract}
This article aims to propose reflections about the care of school demand, specifically the difficulty in learning, made by psychologists working in the network of Secondary Health Care of the city of Cuiabá, Mato Grosso. This study is based on the critical perspective in Psychology and was conducted from a qualitative research we seek to identify the meaning that professionals attribute to the school complaints, the theoretical approaches that underpin and tools and methodologies used in practice. The results corroborate previous studies in that school complaints are one of the major requests received in health units areunderstood as a phenomenon resulting from the child's problems, parents and inadequate teaching techniques. The results also point to a mismatch between the proposed service network of Secondary Health Care and the care of school demand.
\end{abstract}

Keywords: School and Educational Psychology; school difficulties; psychologist performance.

\section{Queja escolar y atención psicológico en la red de salud: contribuciones para debate}

\section{Resumen}

Este artículo tiene por objetivo proponer reflexiones sobre la atención a la queja escolar, específicamente la dificultad en el aprendizaje, hecho por psicólogos que actúan en la red de Atención Secundaria a la Salud del municipio de Cuiabá, estado de Mato Grosso. El estudio está fundamentado en la perspectiva crítica en Psicología y se realizó a partir de una investigación cualitativa en que se busca identificar el significado que los profesionales atribuyen a la queja escolar, los abordajes teóricos en que se fundamentan y los instrumentos y metodologías utilizados en la práctica. Los resultados corroboran investigaciones ya realizadas en que las quejas escolares constituyen una de las mayores demandas recibidas en las unidades de Salud siendo comprendidas como un fenómeno decurrente de problemas del niño, de los padres y de técnicas de enseñanza inadecuadas. Los resultados también apuntan para una incompatibilidad entre la propuesta de atención de la red de Atención Secundaria a la Salud y la atención a la demanda escolar.

Palabras clave: Psicología Escolar; dificultades escolares; actuación del psicólogo. 


\section{Introdução}

A sociedade do século $X X I$, estabelecida sob o signo dos avanços científicos e tecnológicos, apesar de equipada com poderosas engenhocas cibernéticas, sofre com grandes e graves problemas decorrentes de um sistema calcado na concentração de riquezas e nas contradições sociais. Dentre os problemas sociais despontam a exclusão, a violência, a desigualdade, o preconceito e o fracasso escolar que, segundo Bock, Furtado \& Teixeira, (2008) produzem sofrimento e humilhação social.

O fracasso escolar, compreendido aqui como a não aprendizagem de conteúdos escolares e que resulta na repetência e na evasão, tem sido considerado como um fenômeno complexo, histórico, de grave repercussão na sociedade, gerador de exclusão e discriminação, por deixar um grande número de crianças à margem do processo de escolarização e, portanto, da sociedade (Souza, 1993; Collares \& Moysés, 1996; Machado \& Souza, 1997; Moysés \& Collares, 1997; Patto, 1990, 2010; Degenszajn, Roz \& Kotsubo, 2001; Angelucci, Kalmus, \& Paparelli, 2004; Lessa \& Facci, 2009; Checchia, 2010).

No atual contexto, a Psicologia é convocada a olhar esses fenômenos sociais sob uma perspectiva que contemple sua contextualização histórica e cultural e a sua transformação. A escolha desta temática surgiu das experiências de estágios realizados durante o curso de graduação em Psicologia nas escolas de Educação Infantil municipais e no Centro de Atenção Psicossocial Infantil (CAPSi), ambos no município de Cuiabá, quando reiteradas queixas eram feitas sobre as crianças com dificuldades de aprendizagem e que, por isso, deveriam ser encaminhadas para tratamento com neurologistas, psiquiatras e psicólogos. No CAPSi, inúmeros prontuários registravam o encaminhamento de crianças pelas escolas com o pré-diagnóstico de "dislexia, distúrbios/ transtornos ou déficit de aprendizagem".

O alto número de queixas escolares suscitou nosso interesse em saber para onde as crianças eram encaminhadas e, ao buscarmos esta informação, chegamos à rede de Atenção Secundária à Saúde, especificamente as Policlínicas da cidade de Cuiabá.

Para a realização deste estudo, desenvolvemos uma pesquisa qualitativa, no ano de 2012, cujo objetivo foi investigar a prática dos psicólogos que atendem a demanda da rede pública em relação à queixa de não aprendizagem no Município de Cuiabá, Estado de Mato Grosso e discutir tanto o fenômeno quanto a prática desses profissionais para o seu enfrentamento.

O referencial teórico adotado repousa na perspectiva crítica em Psicologia Escolar, de modo que os pressupostos e as diretrizes norteadoras da análise estão ancoradas na concepção de homem como um ser ativo, social e histórico, que constrói sua existência a partir de suas ações sobre a realidade.

\section{Fundamentos Teóricos}

O fracasso escolar extrapolou os muros do contexto escolar e se tornou um grave problema social ampliando a exclusão e o sofrimento ético-político de milhares de brasileiros. No Brasil, os registros estatísticos do PNAD/IBGE (Ministério da Educação [MEC], 2011a), referentes ao ano 2009 e divulgados em 2010, demonstram que a educação está longe de ser satisfatória, pois apontam que a taxa de analfabetismo é de $2,5 \%$, entre crianças de 10 a 14 anos, e de $9,7 \%$, entre jovens de 15 anos ou mais e, ainda, o índice de crianças de 10 a 14 anos com mais de dois anos de atraso escolar era de $13 \%$.

Tabela 1. Taxas de distorção idade-série, de abandono e de reprovação em 2010

\begin{tabular}{lccc}
\hline & $\begin{array}{c}\text { Ensino } \\
\text { Fundamental } \\
\text { anos iniciais }\end{array}$ & $\begin{array}{c}\text { Ensino } \\
\text { Fundamental } \\
\text { anos finais }\end{array}$ & $\begin{array}{c}\text { Ensino } \\
\text { Médio }\end{array}$ \\
\hline $\begin{array}{l}\text { Taxa de } \\
\text { distorção } \\
\text { idade-série }\end{array}$ & & & \\
\hline Brasil & $18,5 \%$ & $29,6 \%$ & $34,5 \%$ \\
\hline Mato Grosso & $12,9 \%$ & $24,6 \%$ & $35,5 \%$ \\
\hline Cuiabá - MT & $10,3 \%$ & $21,1 \%$ & $31,7 \%$ \\
\hline $\begin{array}{l}\text { Taxa de } \\
\text { abandono }\end{array}$ & $1,8 \%$ & $4,7 \%$ & $10,3 \%$ \\
\hline Brasil & $0,7 \%$ & $1,6 \%$ & $11,2 \%$ \\
\hline Mato Grosso & $0,5 \%$ & $1,6 \%$ & $9,8 \%$ \\
\hline Cuiabá - MT & & & $17,6 \%$ \\
\hline $\begin{array}{l}\text { Taxa de } \\
\text { reprovação }\end{array}$ & $3,3 \%$ & $4,5 \%$ & $12,5 \%$ \\
\hline Brasil & $3,6 \%$ & & \\
\hline Mato Grosso & & & \\
\hline Cuiabá-MT & & & \\
\hline Fonte: MEC/NEP/DT & & \\
\hline
\end{tabular}

Fonte: MEC/INEP/DTDIE (2011)

\begin{tabular}{lccc}
\hline $\begin{array}{l}\text { Região } \\
\text { Norte (2010) }\end{array}$ & $11,4 \%$ & $12,3 \%$ & $10,6 \%$ \\
\hline $\begin{array}{l}\text { Região } \\
\text { Nordeste } \\
\text { (2010) }\end{array}$ & $11,1 \%$ & $15,0 \%$ & $9,5 \%$ \\
\hline $\begin{array}{l}\text { Região } \\
\text { Sudeste } \\
\text { (2010) }\end{array}$ & $5,5 \%$ & $10,5 \%$ & $13,9 \%$ \\
\hline $\begin{array}{l}\text { Região Sul } \\
\text { (2010) }\end{array}$ & $6,8 \%$ & $14,1 \%$ & $14,4 \%$ \\
\hline $\begin{array}{l}\text { Região } \\
\text { Centro- } \\
\text { oeste (2010) }\end{array}$ & $7,4 \%$ & $11,4 \%$ & $15,3 \%$ \\
\hline
\end{tabular}


No Estado de Mato Grosso, os dados do PNAD/IBGE (MEC, 2011b), relativos ao ano 2009 e divulgados em 2010, demonstram que a taxa de analfabetismo é de 1,2\% entre crianças de 10 a 14 anos, e de 10,2\%, entre jovens de 15 anos ou mais. $O$ índice de crianças (10 a 14 anos) com mais de dois anos de atraso escolar é de 9,5\%.

Em 2010, o Brasil, o Estado de Mato Grosso e o Município de Cuiabá, de acordo com a fonte MEC/INEP/DTDIE (MEC, 2011c), apresentaram os seguintes dados quanto às taxas de distorção idade-série, de abandono e de reprovação:

Os dados estatísticos apresentados constituem um retrato de que o fracasso escolar é uma realidade na educação brasileira, tanto que o próprio Ministério da Educação, mediante a Secretaria de Educação Infantil e Fundamental e, particularmente, do Departamento de Políticas Educacionais, publicou, em 2005, o documento: Elaboração de Políticas e Estratégias para a Prevenção do Fracasso Escolar - Documento Regional, Brasil, intitulado Fracasso Escolar no Brasil: Políticas, programas e estratégias de prevenção ao fracasso escolar (MEC/SEIF/DPE, 2005).

Mais recentemente, em 2011, o MEC lançou a publicação Jovens de 15 a 17 anos no Ensino Fundamental - caderno de reflexões -, que aborda as causas do fracasso escolar e os desafios das redes de ensino e da comunidade na busca de condições favoráveis ao aprendizado desses jovens (Correio Braziliense, 2011).

O dicionarista Aurélio (Ferreira, 1986, p. 806) apresenta, dentre outras, a seguinte definição para a palavra fracasso: "desastre; ruína; perda; mau êxito; malogro". Ao adicionar ao termo fracasso o qualificativo escolar, pode-se afirmar que fracasso escolar corresponderia ao mau êxito na escola, configurando, sob a ótica tradicional, como a reprovação, a não aprendizagem e a evasão escolar. Entretanto, o fracasso escolar, no sentido mais abrangente, alcança além da reprovação e da evasão, a aprovação com baixo índice de aprendizagem, que não está nos dados estatísticos oficiais.

Para Cordié (1996, citado por Degenszajn e cols., 2001, p. 107), o fracasso escolar é algo recente, na medida em que surge com a instauração da escolaridade obrigatória no fim do século XIX e tomou um lugar considerável nas preocupações dos teóricos contemporâneos em consequência de uma mudança radical da sociedade.

Com o advento das ciências, especificamente, das ciências psicológicas, essa questão passou a ser analisada a partir de uma ótica individualista em que se considera o problema como sendo da criança. Para Machado e Souza (1997), muitas das dificuldades manifestadas pelos alunos tornam-se evidentes no momento do ingresso da criança na escola, quer pelas habilidades psicomotoras exigidas, quer pela tarefa de adaptação a um ambiente novo, profundamente diverso do ambiente familiar. Assim, considera-se que a criança seria portadora de dificuldades emocionais e conflitos internos que se revelam quando esta toma contato com um ambiente desafiador e hostil, como o escolar.

Nesse enfoque, autores como Patto (1990), Souza (1993), Machado e Souza (1997), destacam um predomínio do modelo clínico no atendimento das questões escolares, com total desprezo pelo que se passa na escola, nas relações ali instituídas, nos problemas decorrentes da relação professor-aluno, no histórico da vida escolar do aluno, e, acima de tudo, com as políticas que determinam e atravessam o cotidiano escolar.

Degenszajn e cols. (2001) assinalam que, de um modo geral, as crianças ou jovens que fracassam na escola e que são encaminhados para os psicólogos trazem consigo a suspeita de deficiências de uma ou de várias funções cognitivas, como alteração da percepção de formas, distúrbios da fala, distúrbios da linguagem escrita, dentre outros.

Segundo Angelucci e cols. (2004), diversas pesquisas realizadas no Brasil na década de 80 denunciam essa visão, a exemplo das publicações constantes da Revista Brasileira de Estudos Pedagógicos (INEP), que relatam a força da crença de que as crianças com queixa escolar encaminhadas para atendimento em serviços de Psicologia sofrem as consequências da pobreza, apresentam déficit cognitivo, são de famílias desestruturadas, e, ainda, são vítimas de carência afetiva.

Outra investigação que corrobora essa crença é a pesquisa conduzida por Collares e Moysés (1996), com professores e diretores da rede pública em Campinas, Estado de São Paulo, demonstrando que 92\% dos entrevistados acreditavam que o fracasso escolar deve-se a problemas emocionais ou neurológicos das crianças e a totalidade afirmou que as dificuldades escolares têm como causas problemas biológicos e de desnutrição. Dessa forma, excluem-se das explicações as questões políticas e econômicas do fracasso escolar, marginalizando ainda mais a população das classes pobres.

Apesar dessas concepções e crenças, a Psicologia, atualmente, tem lançado um novo olhar sobre o fenômeno do fracasso escolar, buscando uma análise e compreensão para além de um caso clínico e individual e fazendo sua articulação com o contexto social, cultural e histórico.

Checchia (2010) assinala que o movimento crítico em Psicologia Escolar foi intensificado a partir dos anos 1970 e início de 1980 com a publicação de textos produzidos por Maria Helena Souza Patto, entre 1981 e 1984, em que a autora denuncia a naturalização e o caráter ideológico presentes em concepções e práticas no campo da Psicologia. Com base nos fundamentos do pensamento marxista e nos princípios do materialismo histórico dialético, Patto enfatiza a constituição social e histórica dos fenômenos escolares e explicita a complexidade de fatos implicados no processo educacional, como elementos sociais, históricos, institucionais, políticos e ideológicos. Dessa forma, o pensamento crítico envolve a investigação das raízes dos fenômenos estudados, em oposição à sua naturalização.

Destacamos que a perspectiva crítica em Psicologia Escolar tem como pontos de ancoragem a compreensão do homem como um ser ativo, social e histórico, e a desnaturalização do mundo psicológico, opondo-se às concepções que apregoam a existência de uma natureza humana, justamente por compreender o indivíduo como ser determinado 
histórica e socialmente, ou seja, por conceber o homem nas suas relações e em seus vínculos sociais, pela sua inserção em um contexto social e em um dado momento histórico.

Para Heckert e Barros (2007), a Psicologia pode contribuir para a produção de atitudes que dignificam a vida produzindo uma política de invenção, calcada em uma rede de produção de saberes coletivos que produzem intervenções no que está instituído no âmbito do debate sobre o fracasso escolar, a fim de que se faça a transição de uma concepção de individualização-privatização para uma contextualização-coletivização do fenômeno.

Nesse sentido, na atuação frente ao fracasso escolar, a abordagem crítica em Psicologia Escolar tem como objetivo desenvolver estratégias que possibilitem, ao mesmo tempo, a potencialização dos sujeitos envolvidos, a fim de que estes tenham condições de se colocarem como protagonistas da cena social, e, coletivamente, a construção de mecanismos para o enfrentamento dos problemas escolares.

\section{A pesquisa}

A escolha das Policlínicas do Município de Cuiabá-MT como locus desta pesquisa deveu-se ao fato de serem essas unidades um dos serviços em que o atendimento psicológico é disponibilizado para a população para o atendimento das mais diversas demandas, inclusive, aquelas relacionadas com a queixa escolar.

Assim, a presente pesquisa, de caráter qualitativo, foi realizada nas Policlínicas do Município de Cuiabá-MT que, na estrutura organizacional da Secretaria Municipal de Saúde, se subordinam à Diretoria de Atenção Secundária - Coordenação de Atenção Secundária, compondo a rede de organização do modelo considerado de média complexidade na Rede de Atenção à Saúde no âmbito do Sistema Único de Saúde (Prefeitura Municipal de Cuiabá, 2011).

As Policlínicas são unidades institucionais descentralizadas de Saúde que ofertam serviços ambulatoriais especializados (por agendamento) nos dias úteis e pronto-atendimento (infantil e adulto) em urgência e emergência 24 horas. Dentre os serviços de especialidade médica, desatacam-se: clínica geral; pediatria; cardiologia; psiquiatria e psicologia (Prefeitura Municipal de Cuiabá, s.d.).

Participaram desta pesquisa quatro profissionais psicólogo e psicólogas - que atuam nas quatro Policlínicas do município. Utilizamos a entrevista semiestruturada para a coleta de dados e, ao final da pesquisa, apresentamos, aos profissionais, o relatório final com a análise de dados. Todos os participantes aprovaram o relatório.

\section{Resultados e Discussão}

Os dados coletados foram analisados a partir das categorias: significado que os profissionais atribuem aos problemas de aprendizagem; abordagem teórica predominante no atendimento; instrumentos ou metodologias utilizadas; contribuição da Psicologia ao enfrentamento da queixa. Os participantes foram denominados aqui de E1, E2, E3 e E4.

Os psicólogos foram unânimes em afirmar que as unidades de Saúde têm como uma de suas maiores demandas as queixas escolares e, dentre elas, os problemas de aprendizagem. Os alunos são encaminhados pelas próprias escolas, pela família, pelo Conselho Tutelar e pelos juízes, como revelam os seguintes trechos das entrevistas:

Eu recebo demanda, muita demanda de escolas, através da própria escola, através da própria família que vem aqui e através de Conselho Tutelar, através do juizado... (E1).

Bom, aqui nós recebemos, né? Eu recebo. Até que no momento está menos, porque dei uma barrada, né? E a queixa é baixo rendimento escolar, problema de aprendizagem e hiperatividade... (E2).

A demanda é bem alta, né? Eu acredito que fica assim em segundo lugar... Primeiro é a espontânea, que os pais mesmos que procuram e segundo da escola. Muita demanda mesmo. E de toda região de Cuiabá e também do interior... (E3).

Eu recebo muitos pacientes que vêm com seus pais, avós, tios sempre com um bilhetinho da escola solicitando atendimento. Às vezes, nem vem com um papel formal. A escola que pede por alguns motivos. Um deles é quando a criança não aprende... (E4).

Essas respostas corroboram algumas pesquisas (Souza, 1993; Cabral \& Sawaya, 2001) que apontam que a queixa escolar tem sido uma das queixas mais frequentes feitas aos psicólogos que atendem crianças na área da Saúde.

No que se refere ao significado que os psicólogos atribuem ao fracasso escolar, podemos constatar que os profissionais consideram-no como um fenômeno oriundo de questões individuais ou problemas biológicos da criança; ausência de acompanhamento dos pais e/ou familiares no processo de escolarização; baixa condição financeira para custear os estudos e, ainda, falta de técnica adequada dos professores.

Nesse sentido, os resultados obtidos indicam que, embora os entrevistados possuam concepções diferenciadas acerca de suas causas, elas podem ser agrupadas, valendo-se da classificação apresentada por Angelucci e cols. (2004), predominantemente, nas seguintes formas:

a) fracasso escolar decorre de problemas psíquicos/ emocionais da criança ou das condições culturais e econômicas dos pais e/ou familiares - culpabilização das crianças e dos pais/família -, como demonstram as seguintes afirmações dos entrevistados:

Falta esses pais é monitorarem mais, cercar a criança de mais recursos... Eles não têm condições financeiras para isso; mas eu acho que um gibi, sabe, é... um jogo que possa estimular essa criança, eu acho que têm condições sim. (E3). 
Eu procuro ver antes de tudo quando a criança tem problemas... Por exemplo, vamos identificar, ele tem um problema, ela é disléxica, ela troca letras, ou ela gagueja, ela troca os símbolos... Mas, assim o que é que faz com que essa criança não queira enxergar, não queira. E, assim, já teve um caso de uma criança que chegou num certo ponto e ela não ia mais pra frente, ela não aprendia mais. Aí eu fui, durante os atendimentos, eu fui descobrir que os pais não sabiam mais que aquela série, a quarta série da criança. Parece que ela não se permitia passar do pai. Era um menino e não permitia saber mais que o pai. Então, assim, eu faço uma avaliação e um estudo na área subjetiva enquanto sujeito. Não em si no que a escola, na educação formal propriamente dita, sabe. O que está limitando essa criança que ela não quer ver o mundo, não quer conhecer o mundo. Porque você ter acesso aos símbolos, as letras é o universo que se abre. E tem muitas crianças que não são crianças sem inteligência, de forma alguma, mas tem uma dificuldade com os símbolos. Eu recebo muito crianças de 11, 12 anos que tem essa dificuldade. (E4).

b) fracasso escolar como efeito de técnicas de ensino inadequadas ou de falta de atualização dos professores culpabilização do professor -, conforme relatos dos entrevistados a seguir transcritos:

Características do fracasso escolar para mim... É..., bem, essa falta de atualização... da escola em si, dos professores em receber os alunos..., falta da informatização dos dados... (E1).

Eu observo em algumas sessões... Até mando escrever, fazer ditados, as coisas... observo. Quando vejo que há algum problema emocional que está bloqueando alguma coisa, aí fica... Mas, quando eu vejo que não tem, eu encaminho, eu devolvo lá e mando a escola dar conta deles... É problema assim, acho que é, como te falei, é uma questão de alfabetização, da base lá... Aqui, eles choram para vir aqui. Diferente de escola que não gostam de ir à escola, não gostam de escrever. Porque para uns a escola é chata. É chata a escola. Não é atrativa, não tem nada. Não é atrativa, é aquela coisa de reproduzir. Passa no quadro, escreve, passa no quadro, escreve, passa no quadro, escreve... (E2).

Os relatos acima estão marcados pela concepção de que a maioria dos casos de fracasso escolar está associada à falta de atualização dos professores, da escola que não é atrativa, inclusive, é considerada "chata pelas crianças", à ausência de formação de base no processo de alfabetização, remetendo, assim, ao entendimento de que a gênese do fenômeno se assenta nas técnicas de ensino inadequadas.

Angelucci e cols. (2004) ainda se reportam a uma terceira classificação acerca do enquadramento do fracasso escolar, que é considerá-lo como questão institucional, em que há culpabilização da escola pela sua falta de estrutura. Porém, neste estudo, não foi identificada nenhuma resposta que correspondesse a essa concepção.
Ressaltamos que um dos entrevistados afirmou que o fracasso escolar é uma questão social, ao pontuar que: "No meu modo de ver, é uma questão social que tá fora do orgânico, mas é social. É uma questão social mesmo." (E1).

A Psicologia, em uma perspectiva crítica, como assevera Patto (2010), ao examinar o fracasso escolar, tem procurado sair da instância do individual, do particular, e tem buscado na esfera social, nas relações de classes, explicações para o fato de uma grande parcela de crianças de uma classe menos favorecida não se apropriar dos conhecimentos escolares. O fracasso escolar somente pode ser compreendido como processo psicossocial complexo. Esclarece a autora que o processo social de produção do fracasso se realiza no cotidiano da escola.

Nessa mesma linha de entendimento, Facci (1991, citada por Lessa \& Facci, 2009) ressalta que a redução das questões educacionais somente à sua dimensão psicológica tem fracassado na tentativa de uma explicação mais ampla sobre a complexidade do processo educacional e sua relação com a sociedade. Nesse sentido, a autora assevera que a crise da escola e seus insucessos são decorrentes da crise da sociedade capitalista, pois esta explica o fracasso da mesma forma com que a burguesia analisa o real.

A respeito da atuação dos psicólogos, especificamente no que se refere à abordagem teórica adotada, os resultados evidenciam que os entrevistados fundamentam-se, de forma unânime, na psicanálise. Porém, um dos entrevistados relatou:

...enxergar a dinâmica da criança e da família da criança, eu incluo a família da criança no trabalho que eu faço, na medida em que eles estão próximos. Às vezes, é..., já veio até professores conversar comigo... Mas eu tenho uma leitura da história da criança, né? Historia orgânica, as vivências que a criança tem... Então, não diria que é puramente psicanalítica a minha abordagem, assim... Eu já enxergo a criança inserida num contexto histórico. É levo em consideração e tem que ser levado em consideração essa parte da história da criança... (E1).

Esse participante refere-se à importância de conhecer e de se considerar a história da criança no atendimento, afirmação que gerou algumas questões: A que história o profissional se refere? Seriam consideradas apenas a história clínica da criança e a história de sua família? Qual contexto seria analisado? Ou seriam considerados a história escolar da criança e o seu contexto escolar?

Patto (2010) aponta que o fracasso escolar deve ser compreendido como parte integrante da vida na escola e esta como expressão das formas que a vida assume na sociedade que a contém. Dessa forma, assim como Patto (2010) e Machado (2000), compreendemos que mais do que a história de vida da criança, o que pode nos fornecer pistas sobre as circunstâncias em que ela não aprende é sua história escolar, com todos os fatos e pessoas que dela participam.

Relativamente ao uso de instrumentos e às metodologias utilizadas, os dados coletados demonstram que os 
profissionais atendem as crianças por meio da escuta individualizada, utilizando-se da associação livre, ludoterapia, desenhos e, de um modo geral, não costumam utilizar testes psicológicos. Apenas um dos entrevistados (E3) referiu-se à aplicação do HTP. Assim, os psicólogos utilizam-se de técnicas que possam facilitar o diálogo com a criança e a compreensão dos aspectos emocionais que possivelmente estejam dificultando a aprendizagem escolar.

Os participantes, de um modo geral, não costumam fazer laudos ou pareceres para as escolas, por entenderem que essa é uma forma de rotular o aluno no contexto escolar e que a emissão desses documentos seria prejudicial para o desenvolvimento da criança, gerando sua exclusão e isolamento social, como revelam nas seguintes respostas:

...Quando é pra se queixar da criança todo mundo assina, vem a assinatura desde a merendeira,... Então, a gente percebe que é só rotulando, sabe, só rotulando, só estigmatizando aquela criança. E eles costumam muito pedir um parecer pra você. E normalmente eu não... Eu recuso. Porque a gente tem a experiência de que esses pareceres, esses laudos que eles querem é pra taxar a criança, sabe, não vai adiantar nada pra eles,... não vai resolver nada. É pra taxar: 'Ah! Aquele ali é hiperativo', 'ah, aquele ali lembra?, é o hiperativo que a psicóloga falou'... Então, assim, eu normalmente, eu não gosto de encaminhar parecer pra escola não... (E3).

Olha as escolas... a mãe sempre me aparece aqui pedindo um laudo. Eu explico para mãe que quem pede laudo é o juiz... Que a gente procura não por um rótulo na criança que está em constante desenvolvimento... Se a criança tem um comportamento este ano não quer dizer que o ano que vem ela vai ter. Então, assim, que eu procuro fazer um papel para a escola, um relatório de atendimento informando que ela esteve tal dia, que foi acolhida naquele dia, que ela veio tantas vezes, que ela apresentou problema de leitura ou alguma coisa, que está sendo trabalhado o histórico familiar dela, que houve uma separação na família... Mas, assim, não colocando, não classificando essa criança dentro de um padrão que possa comprometer o desenvolvimento dela ou até mesmo servindo como um isolamento social dela dentro da escola. (E4).

Destacamos que as manifestações desses profissionais estão contempladas em uma perspectiva crítica em Psicologia Escolar, a qual tem entendido que a presença de laudos psicológicos nas escolas, particularmente nas unidades públicas, costuma funcionar como mecanismo para estigmatizar as crianças das classes populares, rotuladas como portadoras de deficiências biopsicológicas, constituindo-se como meio de exclusão social.

Os entrevistados confirmam o entendimento de Patto (1997) exposto em artigo que faz uma crítica à psicometria de que "encaminhar para diagnóstico os alunos que não correspondem às expectativas de rendimento e de comportamento que vigoram nas escolas é um anseio de professores, técnicos e administradores escolares" (p.47), mas que, sua elaboração podem chegar a se constituir em "crime de lesa cidadania" (p. 47).

Entretanto, a partir dos discursos acima transcritos, observamos que esses psicólogos parecem frustrar as expectativas dos profissionais das unidades escolares, na medida em que não fazem uso de testes e, em consequência, não costumam emitir laudos ou pareceres psicológicos sobre as crianças atendidas.

Ao se recusarem a exercer essa função de diagnosticar as crianças e de emitir laudos psicológicos, esses profissionais corroboram os estudos realizados por Patto (1997) no sentido de que:

... os testes se transformem em artimanha do poder, que prepara uma armadilha para a criança, que acaba vítima de um resultado que não passa de um artefato da própria natureza do instrumento e de sua aplicação, situação tanto mais verdadeira quanto mais o examinando for uma criança pobre e portadora de uma história de fracasso escolar produzido pela escola. (p. 51).

No que diz respeito à contribuição da psicologia frente ao fracasso escolar, todos os entrevistados consideram que os psicólogos podem auxiliar no enfrentamento desse fenômeno; porém, a maioria reconhece que é necessária a presença do profissional da psicologia no contexto escolar, para trabalhar essa e outras demandas escolares em conjunto com os professores, gestores, alunos, pais/familiares:

Eu acho que tem que o psicólogo tem que estar trabalhando na escola junto com os professores, diretores para fazer essa mudança, até auxiliando também os professores... Acho que tem que fazer um trabalho em conjunto. Porque não adianta fazer separado, porque a criança é uma só, então tem que fazer um trabalho em conjunto, não adianta ser separado. 'Ah, esse aqui vai alfabetizar, ah, vai para o psicólogo... (E2).

Eu acredito que tem contribuído sim,... através, por exemplo,... nós temos uma análise crítica dessa demanda... medicamentalização,... e nós temos propostas... de melhoras na educação, nós fizemos reflexões junto dos professores. Os professores se utilizam e escutam com atenção o que a gente tem a propor,... às vezes, são coisas simples de uma criança que os professores precisam ouvir de nós mesmos enquanto profissionais... Propor reflexões... junto aos professores. Eu penso que... os professores estão carecendo das nossas intervenções dentro da escola. Carecendo, assim, porque a escola está padecendo mesmo... Aquele jogo de empurra mesmo, não é da família, não é da escola, não é da família, não é da escola... Mas então é de quem? É da família e da escola. (E1).

Os participantes da pesquisa compreendem o quanto um laudo pode prejudicar uma criança na escola e servir apenas para justificar a exclusão da qual esta já é vítima. 
Também compreendem o caráter dinâmico da vida escolar, quando afirmam que a criança pode ter um comportamento neste ano e outro no ano seguinte. Além disso, afirmam a necessidade da presença do psicólogo na escola para refletir junto com os professores as questões dos alunos e os problemas escolares, mas realizam com as crianças um atendimento clínico individual. Como compreendemos esse paradoxo?

A natureza das Policlínicas é de prestar um atendimento especializado. O psicólogo que atua em Policlínica precisa atender demandas peculiares à sua condição de unidade de Saúde de atenção secundária, que oferece atendimento no modelo clínico, realizado em sessões individuais, inclusive, com obrigatoriedade de cumprimento de quantidade, metas e número de atendimentos, conforme relato de um dos entrevistados: "É eu faço um trabalho de clínica e também de orientação... É clínico... Aqui tem que ser 40 minutos, você tem que atender. Você é obrigada a atender oito pacientes por dia. É obrigado." (E2).

A contribuição da psicologia para o enfrentamento do fracasso escolar perpassa por um esforço que deve ser coletivo, a partir da construção de projetos coletivos, que rompam com as explicações que situam as origens dos problemas educacionais no aluno e/ou em sua família. Pareceu-nos que os profissionais entrevistados querem fazer isso e, de alguma forma, acreditam nessa proposta de trabalho, mas o fato de atuarem em um serviço de atenção secundária à Saúde os impede.

Com efeito, os dados coletados evidenciam que essas unidades, em virtude de sua finalidade precípua de prestação de serviços de Saúde de nível secundário, não possuem estrutura para atender às demandas escolares que requerem o conhecimento do contexto escolar em que a criança está inserida. Dessa forma, se por um lado a teoria nos ensina que não se deve patologizar a queixa e que o atendimento clínico é inadequado para as demandas escolares, por outro, é necessário compreender as limitações de atendimento à queixa escolar na rede de Saúde. Os psicólogos entrevistados apontam a necessidade de interlocução com a escola, mas esta não é uma proposta viável para o tipo de atendimento para o qual são contratados e que, por dever institucional, devem realizar nas unidades de Saúde. Assim, o fato dessas crianças serem encaminhadas para as Policlínicas que compõem a rede de atenção secundária traz em si contradições, visto que tais unidades visam justamente o tratamento de doenças já instaladas.

Um dos entrevistados descreveu o papel das unidades de saúde, ao pontuar que: "Policlínica é atenção secundária,... já é mais voltado a um modelo onde algo já aconteceu, algo tem que se fazer diante daquilo." (E1).

Outro participante também apresentou seu entendimento sobre a atuação do psicólogo nas unidades de saúde em demandas escolares, asseverando que essas instituições caracterizam-se por ser um locus para cuidar da saúde dos usuários, de modo que, na sua concepção, não são um local adequado para tratar de questões escolares.
No entanto, onde eu trabalho, onde acontece na policlínica é um local para cuidar de saúde. Não seria um local. Então, assim eu coloco isso sempre para os familiares, para os pais da criança que, lá na policlínica, é um local de saúde mental; de problemas com criança que está depressiva, a criança não come, não dorme. Não é, não seria um local indicado para tratar problemas escolares. (E4).

Concordamos que as Policlínicas, de fato, não são espaços próprios para o atendimento de crianças com queixas escolares porque, como dito alhures, as Policlínicas compõem a rede de organização do modelo de Atenção Secundária à Saúde que objetiva o tratamento especializado e a reabilitação. Assim, a função institucional das Policlínicas, como unidade de Saúde, por si só, retira-lhes a possibilidade de oferecer atendimento adequado à queixa escolar. Isso equivale a dizer que a atuação dos psicólogos frente às queixas escolares, nesse contexto, fica bastante restrita pelas condições institucionais e estruturais em que estão inseridos.

Justamente a respeito dessa atuação dos psicólogos nas demandas escolares, um importante dado foi colhido correspondente ao entendimento e à conduta de um dos profissionais entrevistados que, enfaticamente, afirmou que não atende à esse tipo de queixa, por não considerá-la demanda da Psicologia, mas da psicopedagogia, como se infere de sua entrevista:

Então, pra mim, déficit de aprendizagem, baixa
concentração, raciocínio lento... Enfim essas questões
todas, memória,... no caso de déficit de aprendizagem,...
é caso para psicopedagogo. Se eu perceber que não tem
nada de fundo emocional... Então, assim, se eu percebo que
a queixa daquele responsável da criança foca na... de déficit
de aprendizagem. Se fica só ali,... não tem mais nenhuma
coisa associada, eu encaminho... Porque eu não cuido. Eu
não estudei psicopedagogia. Eu fiz Psicologia... Eu, eu cuido
de emoções,... de conflitos, de traumas,... É, assim de...
alguns transtornos psíquicos, a gente trata também... Então,
assim, não déficit de aprendizagem. Eu não estudei cinco
anos para ensinar uma criança a ler e a escrever. Então,
essa não é a minha função e eu não desenvolvo isso. (E3).

Este posicionamento levanta questões importantes para reflexão. De alguma forma, o entrevistado revela que a criança com problemas escolares precisa de um profissional que saiba conteúdos escolares e, realmente, os psicólogos não sabem ensinar a ler, a escrever, a calcular, já que essas atividades não fazem parte da formação e nem prática do profissional da Psicologia. Neste caso, os problemas escolares deveriam ser resolvidos por profissionais que compreendem como funciona o processo de aprendizagem da leitura, escrita, cálculo.

Ao fazer tal afirmação, o profissional anuncia que os problemas escolares devem ser resolvidos por pessoas que sabem sobre os processos de escolarização. Acreditamos que esse é um fato incontestável. Porém, importa 
considerarmos, também, que o processo de aprendizagem, nas escolas, extrapola a aprendizagem de conteúdos, ele é atravessado por outras questões como o próprio currículo, a relação entre os pares, o funcionamento, a hierarquia, as emoções, o preconceito, o trabalho do grupo de profissionais. Estas e outras questões acabam definindo o espaço escolar e produzindo situações de sucesso e de fracasso dos alunos e dos profissionais. Nessa perspectiva é que os psicólogos podem e devem se inserir, compreendendo e transformando esse contexto.

Todavia, valendo-se dos estudos de Moysés e Collares (1997), essa inserção do psicólogo no contexto escolar deve ser permeada pela compreensão de que a barreira imposta, cultural e politicamente, às possibilidades de desenvolvimento das crianças é que deve ser objeto de análise, na busca por modos de enfrentamento e superação, e não o seu produto - a diferença construída entre crianças - transformado em mais uma justificativa para a desigualdade social. Essa desigualdade, essas diferenças de possibilidades de pensamento, enfim, a barreira imposta não são fenômenos naturais, não pertencem ao mundo da natureza, mas ao mundo dos homens. A naturalização da desigualdade imposta aos homens requer o ocultamento da discriminação racial, social ou de gênero, sob a aparência de conhecimento científico, alicerçado no campo da Biologia e, mais especificamente, na genética.

Nesse sentido, abrem-se possibilidades para novas investigações e discussões acerca do tema com base em outras vertentes teóricas, a exemplo da ótica dos estudos culturais, segundo a qual, como assinala Stuart Hall (1997a e 1997c, citado por Costa, Silveira e Sommer, 2003), as sociedades capitalistas são lugares de desigualdade no que se refere a etnia, sexo, gerações e classes, sendo a cultura o locus central em que são estabelecidas e contestadas tais distinções. De igual modo, a discussão iniciada neste artigo pode ser objeto de estudo sob a perspectiva da Sociologia da Educação de Pierre Bourdieu, cuja maior contribuição, como assinalam Nogueira e Nogueira (2002), foi estabelecer as bases para um rompimento frontal com a ideologia do dom e com a noção moralmente carregada de mérito pessoal. A partir de Bourdieu tornou-se praticamente impossível analisar as desigualdades escolares, simplesmente, como frutos das diferenças naturais entre os indivíduos.

\section{Considerações Finais}

O percurso deste estudo nasceu da intenção de compreender a prática dos psicólogos que atendem, na rede de atenção secundária à Saúde, a demanda da rede pública de Educação em relação às dificuldades de aprendizagem, no Município de Cuiabá, Estado de Mato Grosso, a fim de abrir mais um campo para discussão e problematização da prática psi, e, ainda, de propiciar a reflexão em torno do compromisso que o profissional da Psicologia, à luz da vertente crítica em Psicologia Escolar, deve assumir para a transformação das relações sociais ainda marcadas pela exclusão, pelo sofrimento ético-político e pela humilhação social.

O interesse em compreender a atuação do psicólogo frente ao fenômeno do fracasso escolar surgiu da constatação de que, nos contextos socioeducativos, ainda prevalecem pensamentos e práticas que tendem a estigmatizar e "patologizar" a criança que apresenta dificuldades no processo de aprendizagem, que é tida como portadora de algum "transtorno mental", por isso, deve ser devidamente avaliada, diagnosticada e tratada por médicos e psicólogos, inclusive, deve ser submetida a tratamento medicamentoso e psicoterápico.

Com este estudo foi possível conhecer as concepções que os profissionais da Psicologia têm acerca do fracasso escolar, identificar as contradições existentes nos discursos que surgem a partir do olhar da saúde sobre essa queixa, bem como conhecer a forma de atuação profissional e as contribuições da Psicologia no enfrentamento desse fenômeno.

Os resultados demonstraram que as queixas escolares constituem uma das maiores demandas recebidas nas unidades de Saúde na cidade de Cuiabá; que os psicólogos consideram que o fracasso escolar decorre de diversas causas, as quais perpassam por problemas individuais da criança, por questões decorrentes de sua situação familiar ou por técnicas de ensino inadequadas; que o fracasso escolar é entendido e tratado sob a perspectiva do olhar da Saúde, sem interlocução com a escola; que a atuação dos psicólogos está, basicamente, fundada na abordagem psicanalítica, no modelo clínico, de atendimento individual, com uso raro de testes psicológicos.

Porém, um dado importante capturado neste estudo que merece realce diz respeito ao fato de que o atendimento nas Policlínicas, inicialmente, somente pode oferecer um olhar da Saúde para a Educação e que, nesse espaço da unidade de Saúde, tem-se poucas possibilidades de fazer algo diferente, dada a dificuldade ou inexistência de interação com a escola. Mesmo assim, os psicólogos se propõem a um atendimento sem laudos, sem diagnósticos, para não rotular mais ainda a criança, que imaginam já estar marginalizada na escola.

Nesse sentido, o estudo realizado permitiu compreender, a partir de seu referencial teórico, que o desafio que se coloca para os psicólogos das Policlínicas frente ao fracasso escolar é de grande monta, na medida em que são chamados a atender uma demanda da Educação com os aparatos e a estrutura peculiares de um contexto de Saúde, o que não lhes oferece condições de transcender a dimensão subjetiva no sentido de compreendê-la no seu contexto escolar, social, histórico e cultural.

Acreditamos que, dada a complexidade das questões que envolvem o atendimento às queixas escolares nas Policlínicas, as discussões aqui tecidas constituem apenas um estímulo para ensejar o seu aprofundamento ou a realização de novas investigações que possibilitem a reinvenção de práticas psi comprometidas com a luta ética pela superação 
das desigualdades sociais geradoras de fracassos e insucessos na escola e fora dela.

\section{Referências}

American Psychological Association [APA] (2013). Publication manual of the American Psychological Association (6th ed.). Washington, DC: Author. Recuperado: 01 ago. de 2013. Disponível: http:// c3icongresso2013.web.ua.pt/wpcontent/uploads/2013/05/ Normas_APA6th.Portugues.pdf .

Angelucci, C.B., Kalmus, J., Paparelli, R. \& Patto, M.H.S. (2004). O estado da arte da pesquisa sobre o fracasso escolar (19912002): um estudo introdutório. Educação e Pesquisa, 30(1), 51-72. Recuperado: 21 nov. de 2011. Disponível: http://www.scielo.br/pdf/ ep/v30n1/a04v30n1.pdf

Correio Braziliense (2011, 13 de junho). Redes de ensino recebem documento que analisa razões de fracasso escolar. Correio Braziliense. Recuperado: 25 out. de 2011. Disponível: http// www2.correiobraziliense.com.br/euestudante/noticias. php?id=20161\&tp=7

Bock, A.M.B., Furtado, O., \& Teixeira, M.L.T. (2008). Psicologias: uma introdução ao estudo da Psicologia. São Paulo: Saraiva.

Cabral, E. \& Sawaya, S.M. (2001). Concepções e atuação profissional diante das queixas escolares: os psicólogos nos serviços públicos de saúde. Estudos de Psicologia, 6 (2), 143-155. Recuperado: 24 nov. de 2011. Disponível: http://www.scielo.br/pdf/epsic/v6n2/7269. pdf

Checchia, A.K.A. (2010). Relato de prática profissional. Desafios de uma intervenção com base numa perspectiva crítica em Psicologia Escolar. Revista Semestral da Associação Brasileira de Psicologia Escolar e Educacional, 14 (2).

Collares, C.A.L. \& Moysés, M.A.A. (1996). Preconceitos no cotidiano escolar: ensino e medicalização. São Paulo: Cortez. Campinas: Unicamp - Faculdade de Educação - Faculdades de Ciências Médicas.

Costa, M.V., Silveira R.H., \& Sommer, L.H. (2003). Estudos culturais, educação e pedagogia. Revista Brasileira de Educação, (23). Recuperado: 27 set. de 2015. Disponível: http://www.scielo.br/pdf/ rbedu/n23/n23a03.

Degenszajn, R.D., Roz, D.P., \& Kotsubo, L. (2001). Fracasso Escolar: uma patologia dos nossos tempos? Equipe multiprofissional de saúde. Health multiprofessional team equipo multiprofesional de la salud. Pediatria, (1), 106-13. Recuperado: 02 nov. de 2011. Disponível: http://pediatriasaopaulo.usp.br/upload/pdf/511.pdf

Ferreira, A.B.H. (1986). Novo Dicionário da Língua Portuguesa. Rio de Janeiro: Editora Nova Fronteira.
Heckert, A.L.C. \& Barros, M.E.B. (2007). Fracasso Escolar: do que se trata? Psicologia e educação, debates "possíveis". Aletheia, n. 25, 1-10. Recuperado: 01 nov. de 2011. Disponível: http://pepsic. bv.org/scielo.php?pid

Lessa, P.V. \& Facci, M.G.D. (2009). O psicólogo escolar e seu trabalho frente ao fracasso escolar numa perspectiva crítica. Em Associação Brasileira de Psicologia Escolar e Educacional (Org.), IX Congresso Nacional de Psicologia Escolar e Educacional (pp. 1-16). São Paulo: Universidade Presbiteriana Mackenzie. Recuperado: 01 nov. de 2011. Disponível: http://www.abrapso.psi. br/documentos/cdIXcompelXCONPEarquivo/19.pdf

Machado, A.M. (2000). Avaliação psicológica na Educação: mudanças necessárias. Em E. Tanamachi, M. Proença, \& M. Rocha (Orgs.), Psicologia e Educação: desafios teórico-práticos. São Paulo: Casa do Psicólogo.

Machado, A.M. \& Souza, M.P.R. (Org.) (1997). Psicologia escolar: em busca de novos rumos. São Paulo: Casa do Psicólogo.

Ministério da Educação e Cultura. Brasil [MEC] (2011a). Números do Brasil. Educação no Brasil. Todos pela Educação. Recuperado: 31 out. de 2011. Disponível: http://www.todospelaeducacao.org.br/ educacao-no-brasil/numeros-do-brasil/brasil/

Ministério da Educação e Cultura [MEC]. (2011b). Mato Grosso. Dados por estado. Números do Brasil. Educação no Brasil. Todos pela Educação. Recuperado: 31 out. de 2011. Disponível: http:// www.todospelaeducacao.org.br/educacao-no-brasil/numeros-dobrasil/dados-por-est...

Ministério da Educação e Cultura [MEC] (2011c). Município. Dados por município. Números do Brasil. Educação no Brasil. Todos pela Educação. Recuperado: 31 out. de 2011. Disponível: http://www. todospelaeducacao.org.br/educacao-no-brasil/numeros-do-brasil/ dados-por-m...

Ministério da Educação e Cultura. Secretaria de Educação Infantil e Fundamental. Departamento de Políticas Educacionais [MEC/ SEIF/DPE] (2005). Elaboração de políticas e estratégias para a prevenção do fracasso escolar - Documento Regional, Brasil: Fracasso escolar no Brasil: políticas, programas e estratégias de prevenção ao fracasso escolar. Brasília: MEC. Recuperado: 25 out. de 2011. Disponível: http://www.porlainclusion.educ.ar/ documentos/Brasil.pdf

Moysés, M.A.A. \& Collares, C.A.L. (1997). Inteligência abstraída, crianças silenciadas: as avaliações de inteligência. Psicologia USP, 8(1). Recuperado: 27 set. de 2015. Disponível: http://www.scielo. br/scielo.php?script=sci_arttext\&pid=S0103-65641997000100005

Nogueira, C.M.M. \& Nogueira, M.A. (2002). A Sociologia da educação de Pierre Bourdieu: limites e contribuições. Educação \& Sociedade, XXIII(78). Recuperado: 27 set. de 2015. Disponível: http://www. scielo.br/pdf/es/v23n78/a03v2378.pdf 
Patto, M.H.S. (1990). A produção do fracasso escolar. São Paulo: ed. T. A. Queiroz.

Patto, M.H.S. (2010). A produção do fracasso escolar: histórias de submissão e rebeldia. São Paulo: Casa do Psicólogo. (Trabalho original publicado em 1999).

Patto, M.H.S. (1997). Para uma crítica da razão psicométrica. Psicologia USP, 8(1), 47-62. Recuperado: 25 out. de 2012. Disponível: http://dx.doi.org/10.1590/S0103-65641997000100004
Prefeitura Municipal de Cuiabá. Secretaria Municipal de Saúde. (s.d.). Cartilha do usuário do SUS/Cuiabá. Cuiabá: Secretária Municipal de Saúde.

Prefeitura Municipal de Cuiabá. Secretaria Municipal de Saúde. (2011). Recuperado: 05 nov. de 2011. Disponível: http:// www. cuiaba.mt.gov.br/secretaria?s=\&\&v=Policlínicas

Souza, M.P.R. (1993). Psicólogos na saúde e na educação: a busca de novos caminhos na compreensão da queixa escolar. Insight: Psicoterapia, 13, 25-27.

\section{Sobre as autoras}

Gercimeire Ramos Moreira (meirermoreira@gmail.com)

Graduanda em Psicologia pela Universidade Federal de Mato Grosso, bacharel em Direito, especialista em Direito do Trabalho e Processo do Trabalho pela Universidade Cândido Mendes - RJ.

Jane Teresinha Domingues Cotrin (janecotrin@gmail.com)

Psicóloga, mestre em Educação (UNESP), doutora em Psicologia Escolar e do Desenvolvimento Humano (IPUSP), professora adjunta do Departamento de Psicologia do Instituto de Educação da Universidade Federal de Mato Grosso.

Pesquisa desenvolvida no curso de graduação em Psicologia da Universidade Federal de Mato Grosso, campus de Cuiabá. 